\author{
Asian Journal of \\ Medical and Biological Research \\ ISSN 2411-4472 (Print) 2412-5571 (Online) \\ www.ebupress.com/journal/ajmbr
}

\title{
Article \\ Quality control and interest of the determination of anti-CCP antibodies and rheumatoid factor in the diagnosis of rheumatoid arthritis
}

\author{
Amoussou $^{1}$ Nathalie Gisèle, Gounongbé ${ }^{1,3}$ Marcelle, Dougnon ${ }^{2}$ Tamègnon Victorien, Zomalheto ${ }^{1,3}$ Zavier, \\ Loko $^{* 2,5}$ Frédéric and Bigot ${ }^{1,4}$ André \\ ${ }^{1}$ Faculté des Sciences de la Santé (FSS/UAC), Benin \\ ${ }^{2}$ Laboratoire de Recherche en Biologie Appliquée (LARBA), Ecole Polytechnique d'Abomey-Calavi (EPAC), \\ Université d'Abomey-Calavi (UAC), 01 BP 2009 Cotonou, Benin \\ ${ }^{3}$ Clinique Universitaire de Rhumatologie du Centre National Hospitalier et Universitaire Hubert Koutoukou \\ Maga (CNHU-HKM) de Cotonou, Benin \\ ${ }^{4}$ Service de la Banque de Sang du Centre National Hospitalier et Universitaire Hubert Koutoukou Maga \\ (CNHU-HKM) de Cotonou, Benin \\ ${ }^{5}$ Centre d'Information et de Recherche en Santé de la Reproduction (CIRSAR), 03BP2343 Cotonou, Benin \\ *Corresponding author: Professor LOKO Frédéric, Laboratoire de Recherche en Biologie Appliquée (LARBA), \\ Ecole Polytechnique d'Abomey-Calavi (EPAC), University of Abomey-Calavi, 01 BP 2009 Cotonou, Benin \\ and Centre d'Information et de Recherche en Santé de la Reproduction (CIRSAR), 03BP2343 Cotonou, \\ Benin.Tel. 00 (229)9799 3157 /95 4541 18; E-mail: loko70frederic@ gmail.com
}

Received: 31 August 2016/Accepted: 18 September 2016/ Published: 29 September 2016

\begin{abstract}
The rheumatoid arthritis (RA) is an auto-immune, rheumatic and chronic inflammatory disease, characterized by joints damage. The early diagnosis of RA allows the initiation of a treatment which offers to the patients more chance of remission and avoids the evolution towards the unrecoverable deformity of joints. The objective of this study is to evaluate the performance of recent tests for the determination of anti -CCP antibodies and FR by ELISA in Benin Republic. This analytical, retrospective ( 2 years 6 months) and prospective (7 months) study allowed us to collect 36 patients meeting the American College of Rheumatology (ACR) criteria for RA and 24 controls. A comparison was made with the latex agglutination test for rheumatoid factors and a search of rheumatoid factors (RF) on the one hand and anti-cyclic citrullinated peptide. In our study, the specificity of anti-CCP assay (100\%) is higher than that of RF-ELISA (91.7\%). The sensitivity of RF-ELISA assay is higher (77.8 \%) than that of anti-CCP assay $(66.7 \%)$. The latex test for rheumatoid factors has a sensitivity of $33.3 \%$. The positive predictive value (PPV) of anti-CCP assay (100\%) is higher than that of RF-ELISA assay $(93.33 \%)$. The positive-likelihood ratio (LR+) of anti-CCP assay is higher than the LR+ of RF-ELISA assay (4.96). The negative-likelihood ratio (LR-) of anti-CCP assay (0.33) is higher than the LR- of RF-ELISA assay (0.24). In conclusion, the anti-CCP assay has the highest specificity and RF-ELISA assay shows the highest sensitivity. In conclusion, the association of the two assays enhances a better diagnosis value for RA.
\end{abstract}

Keywords: anti-CCP rheumatoid factor; rheumatoid arthritis; biological diagnosis

\section{Introduction}

Rheumatoid arthritis (RA) is a chronic, destructive autoimmune disease characterized by synovial joint inflammation that ultimately leads to joint destruction. The consequence is disability and reduction of quality of life. Rheumatoid arthritis affect $0.5-1 \%$ of the world's population (Schellekens et al., 2000; Gabriel, 2001; Silman Pearson, 2002). The prevalence is $0.1 \%$ in Nigeria and Liberia, $0.8 \%$ in Benin with a sex-ratio 2.6/1 (Hadonou, 2002). Age at onset of rheumatoid arthritis is influenced by genetic, hormonal immunological and 
environmental factors (MacGregor et al., 1995; Goemaere et al., 1990; Hutchinson et al., 2001). Genetic risk factors are thought to be responsible for up to 50-60\% of rheumatoid arthritis risk, and the HLA-DRB1 gene has been unequivocally associated with RA susceptibility (Diaz et al., 2011). Other the long course of disease, RA can be diagnosed using the 1987 classification criteria (seven criteria) of the American College of Rheumatology (ACR) (Sizova, 2012). Four of the seven must be present to make the diagnosis of RA. However, six of the seven criteria are frequently observed in diseases other than RA, such as infections, other rheumatoid diseases, among many other conditions (Pinals, 1994). RA is diagnosed primarily according to clinical disease manifestations, and serological support is primarily restricted to the determination of IgM rheumatoid factor (IgM-RF) (Schellekens et al., 2000). Increased levels of rheumatoid factor (RF) can be detected in 50-80\% of RA sera but also encountered in the sera of patients with other connective tissue diseases, patients with infectious diseases, and elderly healthy individuals (Nienhuis and Mandema, 1964). Detection and quantitation of RF have historically relied on agglutination (Waaler-Rose) and turbidity (nephelometry) methods, which preferentially detect the pentameric IgM-RF class (Moore and Dorner, 1993). ELISA and radioimmunoassay technology can also be used to measure IgM-RF, IgA-RF and IgG-RF (Marcelletti and Nakamura, 2003). Other autoantibody-antigen systems described in RA are RA33 (anti-hnRNP-A2), anti-calpastatin, ANCA (antineutrophil cytoplasmic antibodies), ANA (antinuclear antibody), anti-collagen type II, anti-fibronectin and antiGPI (glucose-6-phosphate isomerase) (Westgeest et al., 1987; Schellekens et al., 1998; Mulder et al., 1993; Tan, 1982; Ronnelid et al., 1994; Atta et al., 1995; Schaller et al., 2001). More of these autoantibodies are also present in a variety of other auto-immune diseases. Fortunately, some autoantibody systems with a better specificity for RA also exist as anti-Bip (p68), anti-Sa and APF (antiperinuclear factor), AKA (antikeratin antibody), anti-fillagrin, anti-CCP (anticyclic citullinated peptide antibody) (Vossenaar and Venrooij, 2004). In the early stage of RA, diagnosis is quite challenging. A joint working group of the ACR and European League against Rheumatism (EULAR) was formed to develop new classification criteria of RA (in 2010) to identify individuals at earlier stages of the disease. To classify a patient as having or not having definite RA, a history of symptom duration, joint involvement, and at least 1 serological test (rheumatoid factor [RF] or anticyclic citullinated peptide antibody [anti-CCP] and 1 acute-phase response measure (erythrocyte sedimention rate [ESR] or C-reactive protein [CRP] must be obtained (Sizova, 2012).

Citrulline is nonstandard amino acid, as it is not incorporated into proteins during protein translation. It can, however be generated by post-translational modification of arginine residues by peptidylarginine deiminase enzyme. To standardize method, synthetic citrullinated peptides are used. By using of cyclic peptides, the sensitivity was increased because the peptide adopt a structure in which the citrulline moiety is optimally exposed for antibody binding (Schellekens et al., 2000). With a single cyclic citrullinated peptide, antibodies could be detected in $68 \%$ of RA sera with a very high specificity: 98\% (Vossenaar and Venrooij, 2004; Herold et al., 2005).

Anti-CCP antibodies may be helpful for RA diagnosis because they have moderate sensitive but extremely high specificity to RA than RF. Anti-CCP antibodies can be detected at very early diseases stages, and may be used as indicators of RA progression and prognosis (Rojas-Villarraga et al., 2009).The early diagnosis of RA allows the initiation of a treatment which offers to the patients more chance of remission and avoids the evolution towards the unrecoverable deformity of joints.

In Benin as other sub-Sahara town, RF has been measured in the routine diagnostic laboratory by the latex agglutination test and by cell agglutination method of Waller-Rose because these tests are less expensive than anti-CCP dosage.

The objective of the current study is to evaluate the usefulness of anti-CCP and RF by ELISA method for diagnosing RA and to determine their specificity and sensitivity in comparison with conventional techniques such as latex agglutination test.

\section{Patient, Materials and Methods}

This is a cross analytical retrospective (January 2007-July 2009) and prospective study (July 2009 to January 2010) focused on patients with rheumatic disease and meet the following criteria:

- To be followed in the Clinic of Rheumatology of National and University Hospital Hubert koutoukou Maga (CNHU-HKM) Cotonou

- Rheumatoid arthritis suffer restraint on the basis of at least four ACR criteria, 1987.

- Have given consent for the study 
Furthermore, the witnesses met the following criteria:

- To be followed in the Clinic of Rheumatology of National and University Hospital Hubert koutoukou Maga (CNHU-HKM) Cotonou

- Suffer from other rheumatic disease other than RA (mono-arthritis, back pain, myalgia)

Patients with other connective and subjects with no signs of rheumatic diseases were excluded from the study.

Semi-quantitative and quantitative laboratory data were collected:

- Erythrocyte sedimentation rate (ESR)

- C-reactive protein (CRP)

- complete blood compt (CBC)

- Latex agglutination test (Avitex-RF) for OMEGA

- IgM Rheumatoid Factorby ELISA (EUROIMMUN);

- Anti-CCP ELISA (Ig G) by ELISA (EUROIMMUN).

The data are treated with Epi info version 3.3.2.

\section{Results}

\subsection{Subjects caracteristics}

Sixty patients were recruited for this study with:

- $\quad 36$ patients with RA (case group)

- $\quad 24$ patients with other rheumatic diseases (control group)

In case group, we have, 26 women (72\%) and 10 men (28\%) with arthritis rheumatoid. The sex-ratio is 2.6/1

In control group, we have 18 women $(75 \%)$ and 6 men $(25 \%)$ with another rheumatoid diseases. For patient with RA, mean age was 39.22 years (range, 19 to 58 years). In the control group, the mean age was 57.75 years (range, 44 to 83 years). Subjects with RA are younger than subjects in control group.

\subsection{Biologicals exams}

$59 \%$ of patients with RA had low hemoglobin level (under $10 \mathrm{~g} / \mathrm{dl}$ for women and $11 \mathrm{~g} / \mathrm{dl}$ for men) but the control group had normal hemoglobin level (Table 1).72.2\% of patients with RA had high erythrocyte sedimention rate (ESR). C-reactive protein and white blood cells levels are high for $38.9 \%$ and $22.2 \%$ patients with RA (Table 2). In the control group, $8.3 \%$ subjects have high level for these parameters (Table 2).

Table 1. Repartition of subjects according hemoglobin level.

\begin{tabular}{llclc}
\hline & \multicolumn{2}{c}{ RA } & \multicolumn{2}{c}{ Control } \\
\hline Hemoglobin level & $\mathrm{N}$ & $\%$ & $\mathrm{~N}$ & $\%$ \\
Low & 18 & 50 & 0 & 0 \\
Normal & 18 & 50 & 24 & 100 \\
Total & 36 & 100 & 24 & 100 \\
\hline
\end{tabular}

Table 2. Determination of CRP, ESR and white blood cells.

\begin{tabular}{llclclc}
\hline \multicolumn{1}{l}{ CRP } & & ESR & \multicolumn{2}{c}{ White blood cells } \\
\hline RA group & $\mathrm{N}$ & $\%$ & $\mathrm{~N}$ & $\%$ & $\mathrm{~N}$ & $\%$ \\
High level & 14 & 38.9 & 26 & 72.2 & 8 & 22.2 \\
Normal level & 22 & 61.1 & 10 & 27.8 & 28 & 77.8 \\
Total & 36 & 100 & 36 & 100 & 36 & 100 \\
& & & & & & \\
Control group & $\mathrm{N}$ & $\%$ & $\mathrm{~N}$ & $\%$ & $\mathrm{~N}$ & $\%$ \\
High level & 2 & 8.3 & 2 & 8.3 & 2 & 8.3 \\
Normal level & 22 & 91.7 & 22 & 91.7 & 22 & 91.7 \\
Total & 24 & 100 & 24 & 100 & 24 & 100 \\
\hline
\end{tabular}


Table 3. Repetitivity of anti-CCP and RF-ELISA test.

\begin{tabular}{lll}
\hline & Anti-CCP & RF-ELISA \\
\hline $\mathrm{N}$ & 10 & 10 \\
$\mathrm{X}$ & 0.723 & 0.713 \\
$\sigma$ & 0.0363 & 0.0828 \\
$\mathrm{IC}$ & {$[0.6504-0.7956]$} & {$[0.5478-0.879]$} \\
Experimental CV & $5 \%$ & $11.6 \%$ \\
Euro- immun CV & $4.225 \%$ & $5.12 \%$ \\
\hline
\end{tabular}

Table 4. Inter- serial reproducibility of tests anti-CCP and RF-ELISA.

\begin{tabular}{lll}
\hline & Anti-CCP & RF-ELISA \\
\hline $\mathrm{N}$ & 8 & 12 \\
$\mathrm{X}$ & 0.8025 & 0.7629 \\
$\sigma$ & 0.1276 & 0.1299 \\
$\mathrm{IC}$ & {$[0.5473-1.0577]$} & {$[0.5031-1.0227]$} \\
Experimental CV & $15.9 \%$ & $17 \%$ \\
Euro- immun CV & $6.7 \%$ & $6.13 \%$ \\
\hline
\end{tabular}

Table 5. Linearity of anti- CCP and RF-ELISA.

\begin{tabular}{lll}
\hline & Anti-CCP & RF-ELISA \\
\hline Experimental linearity & $\leq 242 \mathrm{RU} / \mathrm{ml}$ & $\leq 357 \mathrm{RU} / \mathrm{ml}$ \\
Euro-immun linearity & $3-196 \mathrm{RU} / \mathrm{ml}$ & $2-200 \mathrm{RU} / \mathrm{ml}$ \\
\hline
\end{tabular}

Tableau 6. Incidence of positive and negative results of RF- latex and RF-ELISAin patients with RA.

\begin{tabular}{llclc}
\hline & \multicolumn{1}{c}{ RF- latex } & & RF-ELISA \\
\hline Results & $\mathrm{N}$ & $\%$ & $\mathrm{~N}$ & $\%$ \\
Positive & 12 & 33.3 & 28 & 77.8 \\
Negative & 24 & 66.7 & 8 & 22.2 \\
Total & 36 & 100 & 36 & 100 \\
\hline
\end{tabular}

Table 7. Incidence of positive and negative value of RF- latex and RF-ELISA in control group.

\begin{tabular}{llclc}
\hline & & RF- latex & & RF-ELISA \\
\hline Results & $\mathrm{N}$ & $\%$ & $\mathrm{~N}$ & $\%$ \\
Positive & 0 & 0 & 2 & 8.3 \\
Negative & 24 & 100 & 22 & 91.7 \\
Total & 24 & 100 & 24 & 100 \\
\hline
\end{tabular}

Table 8. Incidence of positive and negative results of anti-CCP.

\begin{tabular}{llllc}
\hline & \multicolumn{2}{l}{ RA } & \multicolumn{1}{c}{ Control } \\
\hline Results & $\mathrm{N}$ & $\%$ & $\mathrm{~N}$ & $\%$ \\
Positive & 24 & 66.7 & 0 & 0 \\
Negative & 12 & 33.3 & 24 & 100 \\
Total & 36 & 100 & 24 & 100 \\
\hline
\end{tabular}

Table 9. Comparison of specificity and sensitivity of RF-ELISA, anti-CCP and RF-latex tests.

\begin{tabular}{llll}
\hline & RF-ELISA (\%) & Anti- CCP (\%) & RF-latex (\%) \\
\hline Sensitivity & 77.8 & 66.7 & 33.3 \\
Specificity & 91.7 & 100 & 100 \\
\hline
\end{tabular}


Table 10. Predictive values and likelihood-ratio of RF-ELISA and anti-CCP tests.

\begin{tabular}{lll}
\hline & RF-ELISA & Anti-CCP \\
\hline Paramètres & & \\
PPV & 93.33 & 100 \\
NPV & 73.33 & 66.7 \\
LR+ & 4.96 & Infini \\
LR- & 0.24 & 0.33 \\
\hline
\end{tabular}

\subsection{Quality control for anti-CCP and RF-ELISA test:}

A quality control was performed in laboratories by using positive control. Positive controls have been tested ten times. The optical density (OD) for anti-CCP and RF-ELISA were respectively0.723 and 0.713 . Our coefficient of variation (CV) for anti-CCP (5\%) was comparable to the Euro-immun findings. Nevertheless, experimental coefficient of variation for RF-ELISA (11.6\%) was higher than the Euro-immun findings (4.225\%) (Table 3).

To determine inter-assay variability, we tested positive control with patient sample in all experiment. Coefficient of variation (CV) for anti-CCP and RF-ELISA (15.9\% and $17 \%$, respectively) was higher than that of Euro-immun $(6.7 \%$ and $6.13 \%$, respectively) (Table 4$)$.

Our experimental linearity for anti-CCP test $(\leq 242 \mathrm{RU} / \mathrm{ml})$ is higher than Euro-immun value. For RF-ELISA test, experimental linearity $(\leq 357 \mathrm{RU} / \mathrm{ml})$ is too higher than of Euro-immun (Table 5).

\subsection{Diagnostic characteristics}

In case group, the results were positive in 28 of 36 (77.8\%) for RF-ELISA and 12 of 36 (33.33\%) for RF-latex (Table 6).

In control group, the results were positive in 2 of $24(8.3 \%)$ for RF-ELISA but RF-latex were negative for all subject (Table 7).

The results for anti-CCP were positive in 24 of $36(67.7 \%)$ in RA group and negative for all control group (Table 8).

RF-ELISA sensitivity (77.8 \%) and anti-CCP sensitivity (66.7\%) were higher than that of RF-latex (33.3\%). Anti-CCP and RF-latex specificity (100\%) were higher than that of RF-ELISA (91.7\%) (Table 8).

The positive predictive value (PPV) for anti-CCP was higher than RF-ELISA value but the negative predictive value (NPV) for RF-ELISA was higher than that of anti-CCP (Table 10).

The likelihood-ratio (positive and negative) for anti-CCP was higher than RF-ELISA value.

\section{Discussion}

A total of 36 patients with RA were included in our study. In our study, the sex-ratio (2.6/1) was comparable to the findings of Hadonou (2002). This women predominance was confirmed in literature (Sizova, 2012; Girish and Orlando, 1989; Menkes et al., 2004). In our study, the mean age was 39.22 years.

Anemia is the most frequently biological sign observed during PR. In our study, fifty percent $(50 \%)$ of patient with RA present an anemia. This result was comparable to the findings of Benamour et al. (49.7\%) (1992), but it is higher than the result reported by Leuleu et al. (24\%) and by Mody et al. (40\%)(1989) and lower than that reported by Hadonou (67.4\%) (2002).

The most common anemia in RA is typical of that occurring in other chronic diseases (anemia of chronic disease) and shares characteristic abnormalities of iron metabolism, including decreases in serum iron, total iron-binding capacity, and transferrin saturation despite the presence of normal or increased stainable iron within bone marrow reticulum cells (Cartwright et al., 1971). These alterations in iron metabolism are characteristic of the acute-phase response and have been attributed to the effects of interleukin 1 released by monocytes and tissue macrophages (Dinarello, 1984).

High level of ESR and CRP is a biological consequence of inflammatory diseases.

In our study, $72.2 \%$ of patients have high ESR level. This rate is lower than that reported by Hadonou (2002) and Benamour et al. (1992). $38.9 \%$ of patients with RA were positive for CRP. This rate is lower than reported by Hadonou (87.5\%) (2002).

ESR is an important component of the ACR criteria for disease activity and remission in RA (Pinar et al., 1982). It has been argued that ESR suffers from being responsive to the level of fibrinogen, which is an indirect measure of inflammation. The combination of high CRP plus high ESR was associated with more severe clinical scores, whereas low values for both markers identified patients with the least scores (Marcelletti and Nakarmura, 2003). 
Leukocytosis is often associated with infection; other common causes are hemorrhage, trauma (including surgery), myocardial infarction, malignancies (sarcoma, carcinoma, leukemia, myelosclerosis), poisoning and metabolic disturbances (drugs, chemicals, venoms, tubular necrosis, diabetic coma, gout, liver failure) and autoimmune disorders (rheumatoid arthritis, systemic lupus erythematosus).

Leukocytosis is observed in $22.2 \%$ of patient; this rate is close to Hadonou (2002) value (18\%) and higher than Benamour et al. (2002) value, (18.83\%). This rate is lower than that observed by Leuleu et al. (1983). In our study, the low rates observed is due to majority of patients are tested except the inflammatory period.

Before using in laboratory of anti-CCP and RF-ELISA test, the validity of these tests was determined by evaluation of the precision (repetitivity and inter-serial reproducibility) and the linearity (Bernard, 1985).

The coefficient of variation (CV), also known as relative standard deviation (RSD), is a standardized measure of dispersion of a probability distribution or frequency distribution. It define the relative dispersion of the experimental values. It is used to express the precision and repeatability of an assay. Usually, a method presents a good precision when the CV is lower than $10 \%$ (Bernard, 1985). In our study, the dosage of antibodies antiCCP presents a good precision comparable to that of the manufacturer. The precision obtained for RF-ELISA $(\mathrm{CV}=11.6 \%)$ compared with that fixed by Euro-immun $(5.16 \%)$ is higher but our value is close to the accepted superior limit (10\%). To solve this problem, we used an excess volume of reagent (double volume) for analysis.

The inter-serial reproducibility allows us to define another component of the precision which is the stability of the fixed antigen, the reagent or the control-serum during the storage. Both tests anti-CCP and RF-ELISA RSD were $15.9 \%$ and $17 \%$ respectively. These values are slightly high than those of Euroimmun: $6.7 \%$ and $6.13 \%$ for anti-CCP and RF-ELISA respectively. It can be inferred that the conditions of storage during the air transport affect slightly the stability of the control-serum.

The linearity of anti-CCP and RF-ELISA tests obtained during our study (Table 6) was higher than that obtained by Euro-immun. Due to the heterogeneous nature of human autoantibodies; concentration exceeded sometimes calibration range (0-300 $\mathrm{U} / \mathrm{ml})$. These problems are solved by serum sample dilution.

The limit of detection is the slight serum concentration which gives a detectable analytical signal (Bernard, 1985). The analytical sensitivity indicated by Euro-immun was $1 \mathrm{RU} / \mathrm{ml}$ and $0.3 \mathrm{RU} / \mathrm{ml}$ for RF-ELISA and the anti-CCP respectively. In our context, an exact determination of the analytical sensitivity is not essential in our opinion because these two tests were positive when the concentration was $20 \mathrm{RU} / \mathrm{ml}$ for RF-ELISA and $10 \mathrm{RU}$ $/ \mathrm{ml}$ for anti-CCP. These results are superior to the test limit of detection.

In our study, sensibilities of RF-ELISA (Ig M) and anti-CCP were respectively $77.8 \%$ and $66.7 \%$ ). Our sensibility is close to values obtained by several authors for RF-ELISA: $75 \%$ (Bas et al., 2002), $66 \%$ (Goldbach Mansky et al., 2002), 72 \% (Lee and Schur, 2003), 70 \% (Suzuki et al., 2003) and $68 \%$ (Vallbracht et al., 2004) but is higher than $54 \%$ obtained by Schellekens G.A et al (2000). For anti-CCP, our sensibility is close to value obtained by several authors: $68 \%$ (Schellekens et al., 2000; Bas et al., 2002), $66 \%$ (Lee and Schur, 2003), $64 \%$ (Vallbracht et al., 2004), $65 \%$ (Dubucquoi et al., 2004) and lower than $88 \%$ obtained by Suzuki et al. (2003).

Our specificity for RF-ELISA (91.7\%) is comparable to several authors values: $91 \%$ (1), $87 \%$ (35). It is the same thing for anti-CCP specificity (100\%) which is comparable to several authors' values: 98 \% (Schellekens et al., 2000; Bizzaro et al., 2001), 97 \% (Vallbracht et al., 2004; Zeng et al., 2003).

IgM rheumatoid factor has been commonly used as serological marker of RA. Rheumatoid factors are autoantibodies with specificity for the Fc region of immunoglobulin. Other isotypes of RF have been described: IgG-RF, IgA-RF, IgE-RF. In a study, Swedler et al. (1997) compared the ability of RF isotype measurements to increase specificity for RA diagnosis. IgM-RF, IgA-RF, IgG-Rf were observed in $91 \%, 80 \%$ and $55 \%$ of RA sera, respectively, with specificities of $76 \%, 80 \%$ and $95 \%$, respectively, versus rheumatic disease control. The magnitude of RF positivity in the sera of patients with RA is correlated with the development of progressive and erosive disease (Houssien et al., 1998; Bukhari et al., 2003). In added, high levels of RF were found in the sera of patients with other disease and elderly healthy individuals. But the majority of RF-positive individuals did not develop the disease (Marcelletti and Nakarmura, 2003). This incomplete sensitivity and specificity of RF tests for RA limits their diagnostic usefulness.

To facilitate diagnosis of RA during early stage of the disease, a good serological marker is needed. Antibodies directed to citrullinated proteins provide this ability. To increase the sensitivity of the citrulline-containning peptide ELISA, peptides were modified to adopt a structure in which the citrulline moiety is optimally exposed for antibody binding (Vossenaar and Venrooij, 2004). In several publications, anti-CCP showed a higher specificity and comparable sensitivity than IgM-RF. Schellekens et al. showed that the anti-CCP ELISA is highly specific for RA and can even be detected in up to $35 \%$ of RF-negative sera (Schellekens et al., 2000). 
There are two generations of anti-CCP test. CCP 1 peptide is derived from filaggrin sequences. The CCP 2 test has no homology with filaggrin or other known proteins. The CCP 2 test has a sensitivity comparable to the IgM-RF with a high specificity (Vossenaar and Venrooij, 2004).

Anti-CCP antibodies are usually present before the development of RA symptoms, suggesting that a break in tolerance to citrullination products occurs early in RA development (Nielen et al., 2004). Rantapaa-Dahlqvist et al shown that, anti-CCP 2 was detectable 1.5 to 9 years before onset of the first symptoms of the disease (Rantapaa-Dahlqvist et al., 2003). Nielen et al. shown that, CCP antibodies could be detected in sera up to 14 years before onset of the first symptoms of RA; IgM-RF up to 10 years (Nielen et al., 2004). In a study, Schellekens et al. demonstrated that, combining of anti-CCP and IgM-RF ELISA increased sensitivity and predictive positive value for the diagnosis (Schellekens et al., 2000).

We compared RF-ELISA method with latex fixation test. For this test, the agglutination involved is really a precipitin reaction which takes place on the surface of a large particle (Singer and Plot, 1956). The reactant is adsorbed onto the surface of the particle, and the carrier may the agglutinate or flocculate in the presence of rheumatoid factors. Latex particles are obtained when vinyl monomers are dispersed in water and polymerized by a suitable free radical forming catalyst and produced small spheres of polymers as a colloidal suspension in water (Singer, 1961).

In a review, Singer found positive results between 53 to $94 \%$ (mean $75.8 \%$ ) for patients with RA. But in control subjects (patients with rheumatic and non-rheumatic diseases), the test result was positive in 0 to $15.6 \%$ (mean $5.2 \%$ ). A high incidence of positive test results occurs among the connectivite tissues diseases. RFs are clearly not specific for RA. Latex fixation test was positive in $20.5 \%$ of patients with systemic lupus erythematosus, scleroderma, dermatomyositis, polymyositis and polyarteritis nodosa, all diseases involving connective tissue. Positive titers have been also encountered in serum from patients with sarcoidosis, syphilis, cirrhosis of the liver, hepatitis, lymphomas and viral infections (Singer and Plot, 1956, Menkes et al., 2004). In general, high titers are encountered in active RA but a negative test result does not rule out of the diagnosis of RA. Absence of RF in cases of RA is probably due to other immunologic alterations or deficiency of the immunologic mechanism. It may also be that delayed allergic response rather than classic immunity is responsible for certain forms of rheumatic disease or related connective tissue disorders (Singer, 1961).

According to Humbel, RF-ELISAin comparison with latex method offered many advantages: high sensitivity and specificity and allow measuring IgM and IgA. According several authors, IgA-RF measurement is clinically useful for early prognostic evaluation of recent onset RA (Humbel, 2009; Jorgensen et al., 1996; Teitsson et al., 1984). Presence of IgA-RF was significant associated with extraarticular manifestations and bone erosion (Houssien, 1998).

The predictive positive value (PPV) of anti-CCP (84\%) was higher than that of RF-ELISA (77\%). Schellekens et al are obtained similar value: $84 \%$ and $74 \%$ for anti-CCP and RF-ELISA respectively. The higher PPV of the anti-CCP compared with IgM-RF is explained by the fact that specificity is more important than sensitivity in determining the predictive value of a positive test result. (Schellekens et al., 2000)

The likelihood ratio (LR) of any clinical finding is the probability of that finding in patients with disease divided by the probability of the same finding in patients without disease. Its constitute one of the best ways to measure and express diagnosis accuracy. Positive LR describes how probability of disease shifts when the finding is present and the negative LR describes how probability of disease shifts when it is absent. The bigger the number, the more convincingly the finding suggests that disease (MacGee, 2002). In our study, for RF-ELISA, we obtained 4.96 and 0.24 for LR + and LR - respectively. Nishimura et al. (Nishimura et al., 2007) reported similar results from a multicenter study of 30,235 patients for anti-CCP $(\mathrm{LR}+=4.86, \mathrm{LR}-=0.38)$.

For anti-CCP, LR+ is infinite. The possible explanation is absence of not false-negative anti-CCP results.

According to literature; anti-CCP is a valuable serum marker for the diagnosis of RA. Anti-CCP demonstrated a high specificity and predictive positive value. In added, anti-CCP antibody has the highest ability to predict the future development of RA.

\section{Conclusions}

The aim of this study is to evaluate diagnostic and predictive value of anti-CCP ELISA and RF-ELISA in RA. According to literature, our results show that, the specificity of anti-CCP assay is higher than that of RF-ELISA but the sensitivity of RF-ELISA assay is higher than that of anti-CCP assay. The latex test for rheumatoid factors has low sensitivity. The predictive value of anti-CCP ELISA is better than those of the IgM-RF ELISA and combining of the two tests enhances a better diagnosis value for RA. 
Conflict of interest

None to declare.

\section{References}

Schellekens GA, H Visser, BA de Jong, FHJ van den Hoogen, JMW Hazes, FC Breedveld and WJ van Venrooij, 2000. The diagnostic properties of rheumathoid arthritis antibodies recognizing a cyclic citrullinated peptide. Arthritis \& Rheumatism, 43:155-163.

Gabriel SE, 2001. The epidemioly of rheuatoid arthritis. Rheum. Dis. Clin. North Am., $27: 269-281$.

Silman AJ and JE Pearson, 2002. Epidemiology and genetics of rheumatoid arthritis. Arthritis Res., 4(suppl 3): S265-272.

Hadonou A, 2002. La polyarhtrite rhumatoïde : aspects cliniques, paracliniques et thérapeutiques au CNHU. Thèse Méd. FSS/UAC Cotonou n ${ }^{\circ} 990$.

MacGregor A, W Ollier, W Thomson, W Ollier, D Jawaheer and A Silman, 1995. HLA-DRB1*0401/0404 genotype and rheumatoid arthritis : increased association in men, joung age at onset, and diseases severity. J. Rheumatol., 22 :1032- 1036.

Goemaere S, C Ackerman, K Goethals, F De Keyser, C Van Der Straeten, G Verbruggen, H Mielants and EM Veys, 1990. Onset of symptoms of rheumatoid arthritis in relation to age, sex and menopausal transition. J. Rheumatol., $17: 1620$ - 1622.

Hutchinson D, MP Lynch, RJ Moots, RN Thompson and E Williams, 2001. The influence of current cigarette smoking on the age at onset of rheumatoid arthritis (RA) in individuals with sporadic and familial RA. Reumatology (Oxford), 40 :1068- 1070.

Diaz FJ, A Rojas-Villarraga, Salazar JC, A Iglesias-Gamarra, RD Mantilla and JM Anaya, 2011. Anti-CCP antibodies are associated with early age at onset in patients with rheumatoid arthritis. Joint Bone Spine, 78:175-178.

Sizova L, 2012. Diagnostic value of antibodies to modified citullinated vimentin in early rheumatoid arthritis. Human Immunology, 73:389- 392.

Pinals RS, 1994. Polyarthritis and fever. N. Engl. J. Med., 330:769-774.

Nienhuis RLF and E Mandema, 1964. A new serum factor in the patients with rheumatoid arthritis, the antiperinuclear factor. Ann. Rheim. Dis., 23:302- 305.

Moore TL and RW Dorner 1993. Rheumatoid factors. Cli. Biochem., 26 : 75- 84.

Marcelletti JF and RM Nakarmura, 2003. Assessment of serological markers associated with rheumatoid arthitis. Diagnostic autoantibodies and conventional disease activity markers. Clinical and Applied Immunology Reviews, 4: 109- 123.

Westgeest AA, AM Boerbooms, M Jongmans, JP Vanderbroucke, G Vierwinden and LB van de Putte, 1987. Antiperinuclear factor : indicator of more severe disease in seronegative rheumatoid arthritis. J. Rheumatol., 14: 893- 897.

Schellekens GA, BA de Jong, FHJ van den Hoogen, LB van de Putte and WJ van Venrooij, 1998. Citrulline is an essential constituent of antigenic determinants recongnized by rheumatoid arthritis-specific autoantibodies. J. Clin. Invest., 101: 273- 281.

Mulder AH, G Horst, MA van-Leeuwen, PC Limburg and CG Kallenberg, 1993. Antineutroplil cytoplasmic antibodies in rheumatoid arthritis. Characterization and clinical correlations. Arthritis Rhem., 36: 1054- 1060.

Tan EM, 1982. Antibodies to nuclear antigens (ANA): their immunobiology and medicine. Adv Immunol., 33: 167- 240.

Ronnelid J, J Lyshom, LA Engstrom, L Klareskog and B Heyman, 1994. Local anti-type II collagen antibody production in rheumatoid arthritis synovial fluid. Evidence for an HLA-DR4-restricted IgG response. Arthritis Rheum., 37: 1023- 1029.

Atta MS, KL Lim, DA Ala'deen, RJ Powell and I Todd, 1995. Investigation of the prevalence and clinical associations of antibodies to human fibronectin in systemic lupus erythematosus. Ann. Rheum. Dis., 54:117124.

Schaller M, DR Burton and HJ Ditzel, 2001. Autoantibodies to GPI in rheumatoid arthritis: linkage between an animal model and human disease. Nat. Immunol., 2: 746- 753.

Vossenaar ER and WJ van Venrooij, 2004. Anti-CCP antibodies, a highly specific marker for (early) rheumatoid arthritis. Clinical and Applied Immunology Reviews, 4: 239- 262.

Herold M, V Boeser, E Russe and W Klotz, 2005. Anti-CCP: History and its usefulness. Clinical and Developmental Immunology, 12: 131-135. 
Rojas-Villarraga A, FJ Diaz, E Calvo-Páramo, JC Salazar, A Iglesias-Gamarra, RD Mantilla and JM Anaya, 2009. Familial disease, the HLA-DRB1 shared epitope and anti-CCP antibodies influence time at appearance of substantial joint damage in rheumatoid arthritis. J. Autoimmun., 32: 64- 69.

Girish M and M Orlando, 1989. Rheumatoid arthritis in blacks in South Africa. Annals of Rheumatic Diseases, 48: 69-72.

Menkes CJ, Y Allanore, LE Giraudet, JS Quintrec, P Hilliquin, H Judet, X Puechal and R Tubiana, 2004. La polyarthrite rhumatoïde de l'adulte. Masson : Paris.

Benamour S, B Zeroual and L Fares, 1992. Polyarthrite rhumatoïde au Maroc. A propos de 404 observations. Rev. Rhum. Mal. Ostéo-artic., 59: 801-807.

Leuleu JP, P Dexemple, J Soubeyrand and YB Beda, 1983. La polyarthrite rhumatoïde de la polyarthrite rhumatoïde de l'adulte en Afrique tropicale : à propos de 50 observations en Côte d'Ivoire. Rev. Rhum., 50: 195-203.

Mody MG and LO Meyers, 1989. Rheumatoid arthritis in blacks in South Africa. Annals of the Rheumatic Diseases, 48: 69-72.

Cartwright GE and GR Lee, 1971. Aneamia of chronic disorders. Br. J. Haematol., 21:147-152.

Dinarello CA, 1984. Interleukin-1 and the pathogenesis of the acute phase response. N. Engl. J. Med., 311:14131418.

Pinal RS, J Baum, J Bland, WM Fosdick, SB Kaplan and AT Masi, 1982. Preliminary criteria for clinical remission in rheumatoid arthritis. Bull Rheum Dis., 32: 7- 10.

Opdenakker G, E Willem, WE Fibbe and J Van Damme, 1998. The molecular basis of leukocytosis. Immunology today, 19: 182- 189.

Audigie CL, G Dupont and F Zonszain, 1986. Principes des méthodes d'analyse biochimique. Doin éditeurs: Paris, p.36.

Bernard S, 1985. Biochimie Clinique. Maloine : Paris.

Bas S, TV Pernerger, M Seitz, JM Tiercy, P Roux-Lombard and PA Guerne, 2002. Diagnostic tests for rheumatoid arthritis: comparison of anti- cyclic citrullinated peptide antibodies, anti- keratin antibodies and Ig M rheumatoid factors. Rheumatology, 41:809-814.

Goldbach-Mansky R, J Lee, A McCoy, J Hoxworth, C Yarboro, JS Smolen, G Steiner, A Rosen, C Zhang, HA Menard, ZJ Zhou, T Palosuo, WJ Van Venrooij, RL Wilder, JH Klippel, JrHR Schumacher and HS ElGabalawy, 2000. Rheumatoid arthritis associated autoantibodies in patients with synovitis of recent onset. Arthritis Res., 2: 236- 243.

Lee DM and PH Schur, 2003. Clinical utility of anti- CCP assay in patients with rheumatic diseases. Ann. Rheum Dis., 62:870-874.

Suzuki K, T Sawada, A Murakami, T Matsui, S Tohma, K Nakazono, M Takemura, Y Takasaki, T Mimori and K Yamamoto, 2003. High diagnostic performance of ELISA detection of antibodies to citruillinated antigens in rheumatoid arthritis. Scand. J. Rheumatol., 32:197-204.

Vallbracht I, J Rieber, M Oppermann, F Forger, U Siebert and K Helmke, 2004. Diagnostic and clinical value of anti- cyclic citrullinated peptide antibodies compared with rheumatoid factor isotypes in rheumatoid arthritis. Ann. Rheum. Dis., 63:1079-1084.

Dubucquoi S, E Solau- Gervais, D Lefranc, L Marguerie, J Sibila, J Goetz, V Dutoit, AL Fauchais, E Hachulla, RM Flipo and L Prin, 2004. Evaluation of anti-citrillinated fillagrin antibodies as hallmarks for the diagnosis of rheumatic diseases. Ann. Rheum. Dis., 63 :415-519.

Bizzaro N, G Mazzanti, E Tonutti, D Villalta and R Tozzoli 2001. Diagnostic accuracy of the anti-citrulline antibody assay for rheumatoid arthritis. Clin. Chem., 46: 1089-1093.

Zeng X, M Ai, X Tian, X Gan, Y Shi, Q Song and F Tang, 2003. Diagnostic value of anti-cyclic citrullinated peptide antibody in patients with rheumatoid arthritis. J Rheumatol., 30:1451-1455.

Swedler W, J Wallman, CJ Froelich and M Teodorescu, 1997. Routine measurement of IgM, IgG, and IgA Rheimatoid Factors: High sensitivity, specificity, and predictive value for rheumatoid arthritis. J. Rheumatol., 24: 1037- 1044.

Houssien DA, T Jonsson, E Daview, DL Scott, 1998. Rheumatoid factor isotypes, disease activity and the outcome of rheumatoid arthritis. Comparative effects of differents antigens. Scand. J. Rheumatol., 27: 46- 53.

Bukhari M, M Lunt, BJ Harrison, DGI Scott, DPM Symmons and AJ Silman, 2002. Rheumatoid factor is the major predictor of increasing, severity of radiographic erosions in rheumatoid arthritis. Results from the Norfolk Arthritis Register Study, a large inception cohort. Arthritis Rhem., 46: 906- 912. 
Nielen MMJ, D Van Schaardenburg, HWR Reesink, RJ Van de Stadt, I Van der Horst-Bruinsma and MHM de Koning et al., 2004. Specific antibodies precede the symptoms of rheumatoid arthritis: a study of serial measurements in blood donors. Arthritis Rheum., 50: 380- 386.

Rantapaa-Dahlqvist S, BA DE JONG, E Berglin, G Hallmans, G WadelL and H Stenlund et al., 2003. Antibodies against cyclic citrullinated peptide and IgA rheumatoid factor predict the development of rheumatoid arthritis. Arthr Rheum., 48: 2741-2749.

Singer JM and CM Plotz, 1956. The latex fixation test I. Application to the serologic diagnosis of rheumatoid arthritis. American Journal of Medicine, 21: 888- 896.

Singer JM, 1961. The latex fixation test in rheumatic diseases. American Journal of Medecine, 31: 766- 779.

Menkes CJ, Y Allanore, LE Giraudet, JS Quintrec, P Hilliquin, H Judet, X Puechal and R Tubiana, 2004. La polyarthrite rhumatoïde de l'adulte. Masson : Paris.

Ziff M, 1957. The agglutination reaction in rheumatoid arthritis. J. Chron. Dis., 5: 644-667.

Humbel RL, 2009. Histoire des marqueurs sérologiques de la polyarthrite rhumatoïde. GEAIL'info., 9: 1-3.

Jorgensen I, MC Legouffe, C Bologna, J Brochier and J Sany, 1996. IgA isotype rheumatoid factor in rheumatoid arthritis: clinical implications. Clin. Exp. Rheumatol., 14: 301- 304.

Teitsson I, RH Withrington, MH Seifert and H Valdimarsson, 1984. Prospective study of early rheumatoid arthritis. I. Prognostic value of IgA rheumatoid factor. Ann. Rheum. Dis., 43: 673- 678.

McGee S, 2002. Simplifiying likelihood ratios. J. Gen. Inter. Med., 17: 647- 650.

Nishimura K, D Sugiyama, Y Kogata, G Tsuji, T Nakazawa, S Kawano, 2007. Meta- analysis : Diagnostic Accuracy of Anti-Cyclic Citrullinated Peptide Antibody and Rheumatoid Factor for Rheumatoid Arthritis. Ann. Intern. Med., 146: 797-808. 